Article

\title{
Degradation of Methyl Blue Using Fe-Tourmaline as a Novel Photocatalyst
}

\author{
Xuesen Bian ${ }^{1,2}$, Jianqiu Chen ${ }^{1,3, *}$ and Rong $\mathbf{J i}^{1, *}$
}

1 State Key Laboratory of Pollution Control and Resource Reuse, School of the Environment, Nanjing University, Nanjing 210023, China

2 Nanjing Institute of Environmental Sciences of the Ministry of Environmental Protection of China, Nanjing 210042, China

3 Department of Environmental Science \& Department of Analytical Chemistry, China Pharmaceutical University, Nanjing 210009, China

* Authors to whom correspondence should be addressed; E-Mails: njcjq@yahoo.cn (J.C.); njudoc@163.com (R.J.); Tel./Fax: +86-25-8528-7293 (R.J.).

Received: 10 December 2012; in revised form: 8 January 2013 / Accepted: 14 January 2013 / Published: 24 January 2013

\begin{abstract}
This study investigated the photocatalytic activity of tourmaline by itself. Under irradiation of a $13 \mathrm{~W}, 254 \mathrm{~nm}$ UV lamp, 50\% of methyl blue disappeared in the presence of $130 \mathrm{mg} \cdot \mathrm{L}^{-1}$ tourmaline. The reaction was inhibited by the addition of ethanol, $\mathrm{Cl}^{-}, \mathrm{SO}_{4}{ }^{2-}$ and $\mathrm{Cu}^{2+}$, and promoted a little by addition of $50 \mathrm{mg} / \mathrm{L} \mathrm{Mg}^{2+}$, which supports the inference of involvement of ${ }^{\circ} \mathrm{OH}$ radicals. This is the first proposal of tourmaline as a single photocatalyst without the need to add any artificial chemical products. Results from this study might contribute to the broadened usage of this mineral to approach the goals of saving energy and eliminate direct or indirect environmental pollution.
\end{abstract}

Keywords: tourmaline; methyl blue; photocatalysis; affecting factors

\section{Introduction}

Wastewater from the dye industry is characterized by complex composition [1], high visibility [2] and obvious toxicity [3], thus representing a pollution source deserving special attention [4]. It's estimated that some 600-700 million tons of dye wastewater are released annually into the environment, which represents 10 percent or so, of the total effluents in China [5]. In recent years, lots of efforts have 
been devoted to the treatment of dye wastewaters, which are trying to remove such pollutants by adsorption, active sludge oxidization, ion exchange or ozone treatment. However, such methods often cannot meet all requirements generally considered necessary in wastewater processing, i.e., complete decomposition and detoxification of target contaminants, effective removal of COD as well as satisfactory processability of highly polluted wastewaters. Photocatalysis is a novel method which has attracted a lot of interest in the last several decades [6], due to its innocuity and low cost, as well as its wide applicability for a large variety of pollutants.

Tourmaline is a natural mineral widely distributed in China. The special crystal structure of its trigonal system makes it able to generate a spontaneous electric field within, in which electrons can be driven to flow continually from the negative to the positive pole. The spontaneous field of this mineral makes it useful in various areas of environmental protection: the electric field continually generates anions in the surrounding air, which helps reduce various pollutants like nitrogen oxides, oxygen radicals, etc. The interfacial activity makes it able to act as a cleaning agent instead of detergents. When it is used in water, the facial hydroxyls around it can adsorb contaminant metallic ions [7]. Water $\mathrm{pH}$ can be adjusted by tourmaline through its electric pole and ion exchange effects [8]. In the field of photochemical research, it was found that this mineral can act as the iron source for Fenton reagent to enhance the promotion of photodegradation of Argazol blue [9] and Orange II [10] by $\mathrm{H}_{2} \mathrm{O}_{2}$. Usage of $\mathrm{H}_{2} \mathrm{O}_{2}$ can be regarded as a method of introduction of little additional pollution and thus less hazardous to the environment in some ways, but the production of this chemical itself usually generates various pollutants, which require further treatment. This study is designed to initially investigate the photocatalytic activity of tourmaline mineral by itself without any addition of artificial chemical products, using simulated methyl blue (MB) wastewater as the treatment target.

\section{Results and Discussion}

\subsection{Photocatalytic Degradation of MB by Fe-Tourmaline Powder}

The XRD result of Fe-tourmaline used in this study is shown in Figure 1. The $2 \theta$ values of $13.88^{\circ}$, $20.96^{\circ}, 22.20^{\circ}, 30.14^{\circ}$ and $34.66^{\circ}$ are in accord with those reported by Meng et al. [11], demonstrating the characteristic peaks of Fe-tourmaline. The XRF analysis further showed that the tourmaline powder contains in weight, $48.91 \%$ of $\mathrm{SiO}_{2}, 39.52 \%$ of $\mathrm{Al}_{2} \mathrm{O}_{3}, 5.41 \%$ of $\mathrm{Fe}_{2} \mathrm{O}_{3}, 2.36 \%$ of $\mathrm{CaO}, 1.38 \%$ of $\mathrm{K}_{2} \mathrm{O}, 1.13 \%$ of $\mathrm{Na}_{2} \mathrm{O}, 1.29 \%$ of $\mathrm{MgO}$.

As shown in Figure 2, MB disappeared by $8 \%$ with only UV irradiation. As a common biological stain, it should be stable enough to light. With the addition of tourmaline, the degradation of MB was obviously accelerated. Addition of 3000-mesh tourmaline in the UV photodegradation system resulted in an increase of the MB disappearance rate by $50 \%$. Additionally, no adsorption occurred during this process (Figure 2). The disappearance should only be ascribed to photocatalytic degradation by the tourmaline mineral. To our knowledge, this is the first discovery and proposal of the photocatalytic effects of tourmaline alone. 
Figure 1. XRD spectrum of tourmaline used in this study.

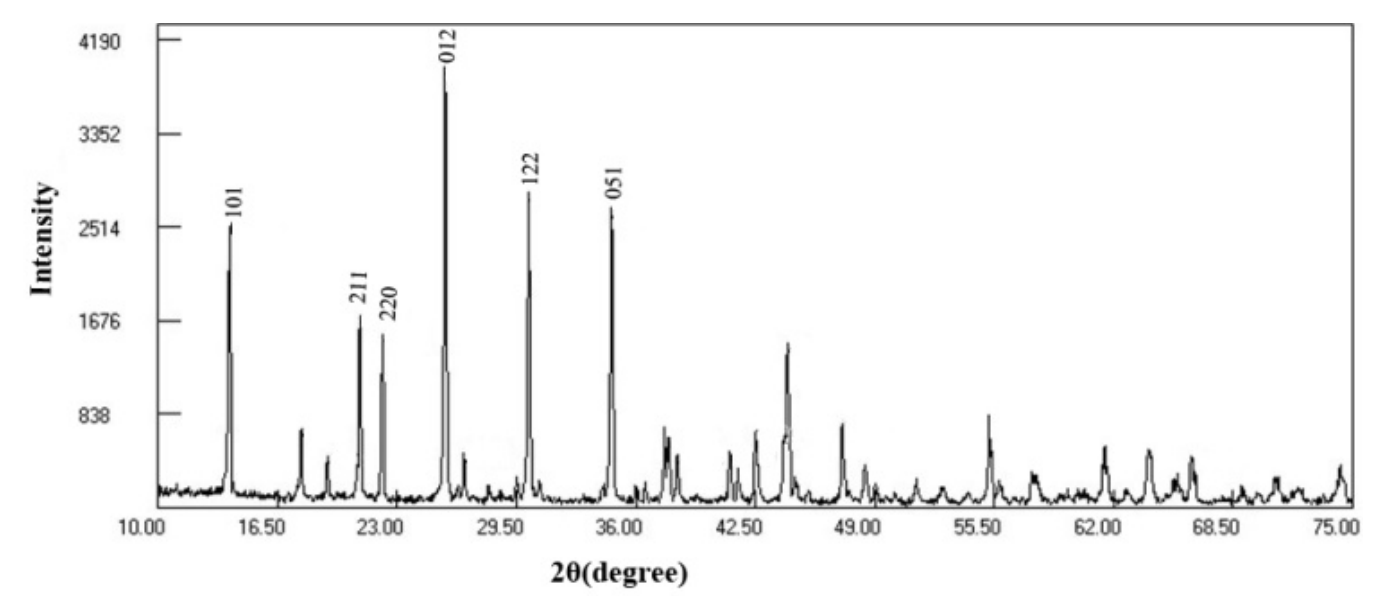

Figure 2. Photocatalytic degradation of $11 \mathrm{mg} \cdot \mathrm{L}^{-1} \mathrm{MB}$ in ultrapure water under UV $254 \mathrm{~nm}$ $(13 \mathrm{~W})$ as air was pumped in at $1 \mathrm{~mL} \cdot \mathrm{s}^{-1}$, and control experiments without $\mathrm{UV}$ or tourmaline.



\subsection{Effect of Ethanol}

As shown in the XRF results, elemental iron exists in the Fe tourmaline used in this study, mainly in the form of $\mathrm{Fe}_{2} \mathrm{O}_{3}$. Photocatalytic degradation catalyzed by $\mathrm{Fe}$ mineral was ascribed to three different mechanisms [12], i.e., that of photoinduced ligand-to-metal charge transfer (LMCT), of semiconductor photocatalysis and of photo-Fenton reactions through the generation and participation of $\mathrm{H}_{2} \mathrm{O}_{2}$. Organic alcohols like methanol, ethanol, $t$-butanol, etc., are typically scavengers of hydroxyl radicals [13]. Ethanol addition exhibited depressing effects for this reaction, as shown in Figure 3, which might support the involvement of ${ }^{\bullet} \mathrm{OH}$ radicals. Photocatalytic reactions through a ${ }^{\bullet} \mathrm{OH}-$ based mechanism were also reported for some other Fe-containing minerals [14,15]. In a photocatalytic system, $\mathrm{Cl}^{-}$may act as a competitor of catalyst adsorption sites or scavenger of ${ }^{\bullet} \mathrm{OH}[16]$ :

$$
{ }^{\circ} \mathrm{Ox}+\mathrm{Cl}^{-} \longrightarrow \mathrm{Cl}^{\bullet}
$$


Figure 3. Photocatalytic degradation of $11 \mathrm{mg} \cdot \mathrm{L}^{-1} \mathrm{MB}$ in ultrapure water under UV $254 \mathrm{~nm}$ $(13 \mathrm{~W})$ as air was pumped in at $1 \mathrm{~mL} \cdot \mathrm{s}^{-1}$, with or without ethanol addition.

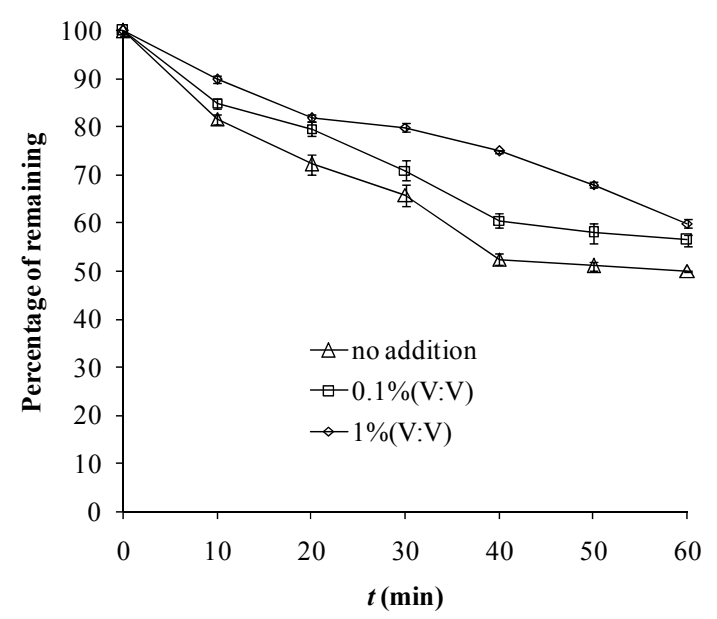

\subsection{Effect of $\mathrm{Cl}^{-}$and $\mathrm{SO}_{4}{ }^{2-}$}

In this study, almost no adsorption seemed to occur between MB and tourmaline powder (Figure 2), thus the adsorption competition can be excluded. In Figure 4, presence of both levels of $\mathrm{Cl}^{-}$depressed the photocatalytic reaction, with the stronger inhibition corresponding to the higher level. This phenomenon might be ascribed to the ${ }^{\circ} \mathrm{OH}$ scavenging effect of $\mathrm{Cl}^{-}$in solution.

Figure 4. Photocatalytic degradation of $11 \mathrm{mg} \cdot \mathrm{L}^{-1} \mathrm{MB}$ in ultrapure water under UV $254 \mathrm{~nm}$ $(13 \mathrm{~W})$ as air pumped in at $1 \mathrm{~mL} \cdot \mathrm{s}^{-1}$, with or without the addition of $\mathrm{Cl}^{-}$or $\mathrm{SO}_{4}{ }^{2-}$.

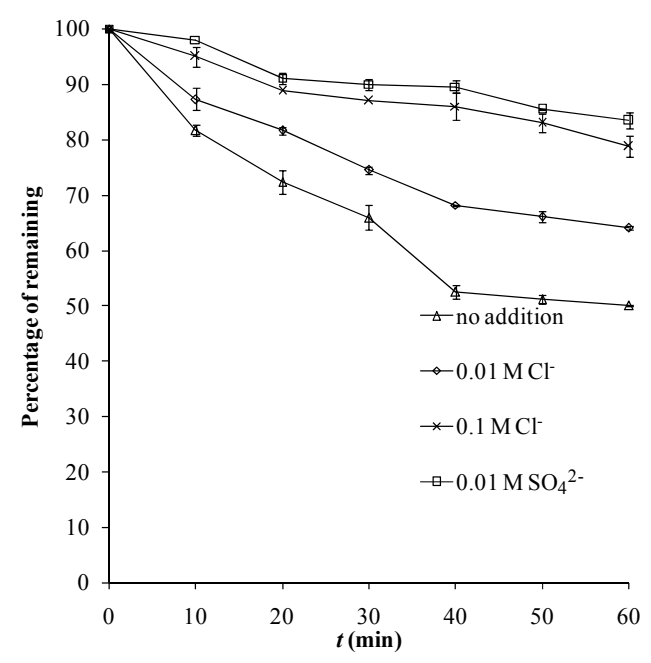

The addition of $\mathrm{SO}_{4}{ }^{2-}$ inhibited the reaction, too. $\mathrm{SO}_{4}{ }^{2-}$ in a photocatalytic system can also act as the scavenger of ${ }^{\bullet} \mathrm{OH}$ radicals [17]:

$$
\mathrm{SO}_{4}{ }^{2-}+{ }^{\bullet} \mathrm{OH}+\mathrm{H}^{+} \longrightarrow \mathrm{SO}_{4}{ }^{2-}+\mathrm{H}_{2} \mathrm{O}
$$

At the same level, the depressing extent of $\mathrm{SO}_{4}{ }^{2-}$ was obviously higher than that of $\mathrm{Cl}^{-}$(Figure 4), which is opposite to the results reported by reference [17]. The product of ${ }^{\bullet} \mathrm{SO}_{4}{ }^{2-}$ can also react with the substrate, which helps reduce the inhibition effect. The stronger extent of inhibition by $\mathrm{SO}_{4}{ }^{2-}$ in this study might be ascribed to the different reaction rates of ${ }^{\bullet} \mathrm{SO}_{4}{ }^{2-}$ with various substrates. 


\subsection{Effect of $\mathrm{Cu}^{2+}$ and $\mathrm{Mg}^{2+}$}

The effects of $\mathrm{Cu}^{2+}$ on a ${ }^{\bullet} \mathrm{OH}-$ mediated heterogeneous photocatalytic system might not be universal. Some researchers have reported an accelerating effect $[18,19]$, due to a mechanism whereby photogenerated electrons are absorbed by the $\mathrm{d}$ orbit holes of copper, and the inhibition of electron-hole recombination will result in more holes reacting with the substrates, but some authors found that $\mathrm{Cu}^{2+}$ slowed down the reaction rate when it reached a certain level [19]. The mechanism might be described as one where $\mathrm{Cu}^{2+}$ can scavenge the photogenerated holes at the surface leading to the suppression of oxidative reaction; $\mathrm{Cu}^{2+}$ might be combined with the organic substrate to form a complex and inhibit the reaction; the conjugation of $\mathrm{Cu}^{2+}$ with photoelectrons might reduce the ${ }^{\circ} \mathrm{OH}$ radicals formed through the reaction of oxygen with electrons. In this study, the presence of $10 \mathrm{mg} \cdot \mathrm{L}^{-1}$ and $50 \mathrm{mg} \cdot \mathrm{L}^{-1} \mathrm{Cu}^{2+}$ obviously inhibited this tourmaline-photocatalyzed reaction (Figure 5 ). Ten $\mathrm{mg} \cdot \mathrm{L}^{-1}$ $\mathrm{Mg}^{2+}$ did not significantly affect the reaction (Figure 5), but when the level of $\mathrm{Mg}^{2+}$ reached $50 \mathrm{mg} \cdot \mathrm{L}^{-1}$, the removal rate was enhanced a bit. This might be due to its absorption of photoelectrons to result in the acceleration of the photoreaction.

Figure 5. Photocatalytic degradation of $11 \mathrm{mg} \cdot \mathrm{L}^{-1} \mathrm{MB}$ in ultrapure water under UV $254 \mathrm{~nm}$ $(13 \mathrm{~W})$ as air is pumped in at $1 \mathrm{~mL} \cdot \mathrm{s}^{-1}$, with or without the addition of $\mathrm{Mg}^{2+}$ or $\mathrm{Cu}^{2+}$.

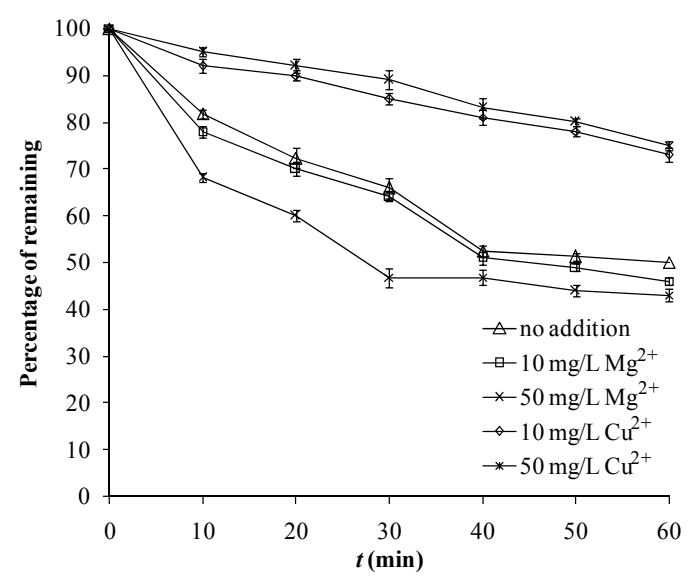

\section{Experimental}

\subsection{General}

Methyl blue (MB) was bought from Sigma-Aldrich (St. Louis, MO, USA). The HPLC mobile phase was of chromatographic grade, while other chemicals were analytical grade, and used without further purification. Fe-tourmaline was purchased from Chuanshi Mineral Processing Factory (Hebei, China). The photoreactor was designed according to Jiang et al. [20]. The $13 \mathrm{~W}$ high-pressure mercury lamp emitting monochromatic light at $254 \mathrm{~nm}$ used in our experiments was purchased from the Xujiang Electromechanical Plant (Nanjing, China). The HPLC system used in this study was an Agilent 1200 series HPLC system, consisting of a G1322 A degasser, a G1311 A Quat Pump, a G1329 A thermostatted autosampler and a G1316A column oven. The column for separation was an Agilent Eclipse XDB-C18 $(5 \mu \mathrm{m}, 4.6 \times 250 \mathrm{~mm})$. The X-ray diffractometer was from X'TRA, with CuKa irradiation. The X-ray fluorescence spectrometer was an XRF-1800 (Shimadzu Co., Kyoto, Japan). 


\subsection{Photocatalytic Degradation of MB by Crude Fe-Tourmaline}

About $11 \mathrm{mg} \cdot \mathrm{L}^{-1} \mathrm{MB}$ solution was prepared by dissolving $5.5 \mathrm{mg} \mathrm{MB}$ into $500 \mathrm{~mL}$ Milli-Q ultrapure water, which was then transferred into the quartz reactor. After that, chemicals for investigation of effects of affecting factors were introduced in (for the effects of ions, sodium salts were used for anions and chloride salts for cations), and $130 \mathrm{mg} \cdot \mathrm{L}^{-1} \mathrm{Fe}$-tourmaline powder was added. The first sample was taken after $1 \mathrm{~h}$ of magnetic stirring of the suspension. The high-pressure mercury lamp was inserted in the hollow of the reactor, with a distance between the lamp and the photoreactor surface of $0.015 \mathrm{~m}$. After equilibrium of the suspension, the lamp was turned on, and photocatalytic degradation was started. All experimental processes were accompanied by vigorous stirring and air-pumping into the system at $1 \mathrm{~mL} \cdot \mathrm{s}^{-1}$. Samples were extracted by a $10-\mathrm{mL}$ injector per internal of $10 \mathrm{~min}$. The sample was then centrifuged $(16,000 \mathrm{~g}, 10 \mathrm{~min})$ and the supernatants separated to be stored under $-20{ }^{\circ} \mathrm{C}$ until HPLC analysis. All experiments were performed in duplicate and at room temperature. The control experiments, without UV irradiation or tourmaline powder, were carried out according to the same procedures.

\subsection{HPLC Analysis and Tourmaline Characterization}

The mobile phase used for the analysis of MB was acetonitrile-water $=40: 60(\mathrm{v}: \mathrm{v})$ isocratically running at a rate of $1 \mathrm{~mL} \cdot \mathrm{min}^{-1}$. The characterization of tourmaline was under the following conditions: the tube voltage and current were $40 \mathrm{kV}$ and $40 \mathrm{~mA}$, respectively. The 2- $\theta$ was measured from 10 to 70 degrees with a step size of 0.02 degree and scan rate of $10 \mathrm{~s} \cdot \mathrm{step}^{-1}$.

\section{Conclusions}

Tourmaline can act as a catalyst for the photocatalytic UV degradation of methyl blue. The primary results showed that the reaction might be mainly through a ${ }^{\circ} \mathrm{OH}$-mediated system. This study is the first to use tourmaline mineral alone as the photocatalyst, the catalytic effect of which needs no pretreatment or addition of other artificially synthesized chemicals. This technology promises a broad utilization in the future.

\section{References}

1. Hessel, C.; Allegre, C.; Maisseu, M.; Charbit, F.; Moulin, P. Guidelines and legislation for dye house effluents. J. Environ. Manag. 2007, 83, 171-180.

2. Nigam, P.; Armour, G.; Banat, I.-M.; Singh, D.; Marchant, R. Physical removal of textile dyes from effluents and solid-state fermentation of dye-adsorbed agricultural residues. Bioresour. Technol. 2000, 72, 219-226.

3. Forgacs, E.; Cserháti, T.; Oros, G. Removal of synthetic dyes from wastewaters: A review. Environ. Int. 2004, 30, 953-971.

4. Saggioro, E.M.; Oliveira, A.S.; Pavesi, T.; Maia, C.G.; Ferreira, L.F.V.; Moreira, J.C. Use of titanium dioxide photocatalysis on the remediation of model textile wastewaters containing azo dyes. Molecules 2011, 16, 10370-10386. 
5. Peng, X.-Y.; Feng, L.; Liu, L. Synergistic degradation of dyeing wastewater by the ultrasound/Fenton method. J. Beijing Univ. Chem. Technol. (Nat. Sci. Ed.) 2007, 34, 122-125 (in Chinese).

6. Šojić, D.; Despotović, V.; Abramović, B.; Todorova, N.; Giannakopoulou, T.; Trapalis, C. Photocatalytic degradation of mecoprop and clopyralid in aqueous suspensions of nanostructured N-doped $\mathrm{TiO}_{2}$. Molecules 2010, 15, 2994-3009.

7. Tang, Y.; Wu, R.; Zhang, $\mathrm{X}$. The mechanism of applying tourmaline to purifying $\mathrm{Cu}^{2+}$-doped waste water. Acta Petrol Miner. 2002, 21, 192-196.

8. Ji, Z.; Jin, Z.; Liang, J.; Wang, J.; Yan, X. Influence of tourmaline on pH value of water. Chin. Environ. Sci. 2002, 22, 515-519.

9. Xu, H.; Prasad, M.; Liu, Y. Schorl: A novel catalyst in mineral-catalyzed Fenton-like system for dyeing wastewater discoloration. J. Hazard. Mater. 2009, 165, 1186-1192.

10. Tokumura, M.; Znad, H.-T.; Kawase, Y. Modeling of an external light irradiation slurry photoreactor: UV light or sunlight-photoassisted Fenton discoloration of azo-dye Orange II with natural mineral tourmaline powder. Chem. Eng. Sci. 2006, 61, 6361-6371.

11. Meng, J.; Liang, J.; Ou, X.; Ding, Y.; Liang, G. Effects of mineral tourmaline particles on the photocatalytic activity of $\mathrm{TiO}_{2}$ thin films. J. Nanosci. Nanotechnol. 2008, 8, 1279-1283.

12. Du, W.; Xu, Y.; Wang, Y. Photoinduced degradation of orange II on different iron (hydr)oxides in aqueous suspension: Rate enhancement on addition of hydrogen peroxide, silver nitrate, and sodium fluoride. Langmuir 2008, 24, 175-181.

13. Yan, X.; Bao, R.; Yu, S.; Li, Q.; Jing, Q. The roles of hydroxyl radicals, photo-generated holes and oxygen in the photocatalytic degradation of humic acid. Russ. J. Phys. Chem. A 2012, 86, 1479-1485.

14. Gondal, M.-A.; Sayeed, M.-N.; Alarfaj, A. Activity comparison of $\mathrm{Fe}_{2} \mathrm{O}_{3}, \mathrm{NiO}, \mathrm{WO}_{3}, \mathrm{TiO}_{2}$ semiconductor catalysts in phenol degradation by laser enhanced photo-catalytic process. Chem. Phys. Lett. 2007, 445, 325-330.

15. Pal, B.; Sharon, M. Photocatalytic degradation of salicylic acid by colloidal $\mathrm{Fe}_{2} \mathrm{O}_{3}$ particles. Chem. Phys. Lett. 2007, 73, 269-273.

16. Abdullah, M.; Low, G.-K.-C.; Matthews, R.-W. Effects of common inorganic anions on rates of photocatalytic oxidation of organic carbon over illuminated titanium dioxide. J. Phys. Chem. 1990, 94, 6820-6825.

17. Wang, K.-H.; Hsieh, Y.-H.; Wu, C.-H.; Chang, C.-Y. The pH and anion effects on the heterogeneous photocatalytic degradation of o-methylbenzoic acid in $\mathrm{TiO}_{2}$ aqueous suspension. Chemosphere 2000, 40, 389-394.

18. Litter, M.-I. Heterogeneous photocatalysis transition metal ions in photocatalytic systems. Appl. Catal. B 1999, 23, 89-114.

19. Okamoto, K.; Yamamoto, Y.; Tanaka, H.; Tanaka, M.; Itaya, A. Heterogeneous photocatalytic decomposition of phenol over $\mathrm{TiO}_{2}$ powder. Bull. Chem. Soc. Jpn. 1985, 58, 2015-2022.

20. Jiang, F.; Zheng, Z.; Xu, Z.; Zheng, S. Preparation and characterization of $\mathrm{SiO}_{2}$-pillared $\mathrm{H}_{2} \mathrm{Ti}_{4} \mathrm{O}_{9}$ and its photocatalytic activity for methylene blue degradation. J. Hazard. Mater. 2009, 164, 1250-1256.

Sample Availability: Samples of the compounds are available from the authors.

(C) 2013 by the authors; licensee MDPI, Basel, Switzerland. This article is an open access article distributed under the terms and conditions of the Creative Commons Attribution license (http://creativecommons.org/licenses/by/3.0/). 